\title{
Soon: a new year, a new name, a new face
}

\author{
J. W. Foppe van Mil - Peter J. A. M. de Smet • \\ Marie Caroline Husson
}

Published online: 14 September 2010

(c) Springer Science+Business Media B.V. 2010

Pharmacy World \& Science is the Official Journal of the Royal Dutch Society for the Advancement of Pharmacy (KNMP) and of the European Society for Clinical Pharmacy (ESCP). The KNMP and ESCP are both eager to promote the clinical function of pharmacists worldwide.

In this issue, we are pleased to present you with two introductions to lectures that will be held during the upcoming 39th ESCP Symposium in Lyon, as well as the abstracts of an ESCP workshop that was held in spring 2010 in Uppsala, Sweden. On both occasions clinical pharmacists will have gathered together from all around the world to present their research and to learn from each other's practices and experience. Although their title says "European", the ESCP is a truly international association. The Dutch pharmacists have a similar international perspective and wish to disseminate the thought that modern pharmacists have clinical roles, in both the hospital and community. These roles need to be supported by high quality research, and that is exactly what PWS strives to publish.

However, the current name of the Journal does not really pay tribute to the concept of clinical pharmacy and pharmaceutical care. Many find the title, "Pharmacy World \& Science", confusing, and wonder what is the scope of the journal. This current name was initially selected in 1979 chiefly to be able to retain the abbreviation PWS (that used to stand for Pharmaceutisch Weekblad Scientific Edition). As of 2011, Pharmacy World \& Science will disappear, and from January, our journal will be re-named the "International Journal for Clinical Pharmacy" (IJCP). This should help immediately, to make the scope more clear; although some still have difficulties to distinguish between clinical pharmacy and hospital pharmacy. But these are two totally different concepts.

Hospital pharmacy is the science that describes the logistics and affiliated pharmaceutical activities and services in a hospital setting. Clinical pharmacy is, concisely, the science that describes and researches the use of medicines (prescribing, dispensing and administration) in patients. The term clinical pharmacy does not relate to a clinic or hospital, but to the clinical (medical) practice.

We look forward to your continued readership and contributions. 